\title{
Article \\ Early Leaf Removal Increases Berry and Wine Phenolics in Cabernet Sauvignon Grown in Eastern Serbia
}

\author{
Dejan Stefanovic ${ }^{1,2, \dagger}$, Nina Nikolic ${ }^{3, \dagger}$, Ljiljana Kostic $^{3}{ }^{\circledR}$, Slavica Todic ${ }^{1}$ and Miroslav Nikolic ${ }^{3, *}$ \\ 1 Faculty of Agriculture, University of Belgrade, Nemanjina 6, 11080 Belgrade, Serbia; \\ dejan.pssnegotin@gmail.com (D.S.); slavicat@agrif.bg.ac.rs (S.T.) \\ 2 Agricultural Extension Service (PSSS), Bukovski Put bb, 19300 Negotin, Serbia \\ 3 Institute for Multidisciplinary Research, University of Belgrade, Kneza Viseslava 1, 11030 Belgrade, Serbia; \\ nina@imsi.bg.ac.rs (N.N.); ljkostic@imsi.bg.ac.rs (L.K.) \\ * Correspondence: mnikolic@imsi.bg.ac.rs; Tel.: +381-11-3058-956 \\ + Both authors contributed equally to this work.
}

Citation: Stefanovic, D.; Nikolic, N.; Kostic, L.; Todic, S.; Nikolic, M. Early Leaf Removal Increases Berry and Wine Phenolics in Cabernet Sauvignon Grown in Eastern Serbia. Agronomy 2021, 11, 238. https:// doi.org/10.3390/agronomy11020238

Academic Editors: Luciano Gristina, Ettore Barone, Rosario Di Lorenzo and Antonino Pisciotta

Received: 17 December 2020

Accepted: 22 January 2021

Published: 28 January 202

Publisher's Note: MDPI stays neutral with regard to jurisdictional claims in published maps and institutional affiliations.

Copyright: () 2021 by the authors. Licensee MDPI, Basel, Switzerland. This article is an open access article distributed under the terms and conditions of the Creative Commons Attribution (CC BY) license (https:// creativecommons.org/licenses/by/ $4.0 /)$

\begin{abstract}
Cluster zone leaf removal is a well-established viticulture practice for improving cluster microclimate and wine quality in cooler climates, while its efficacy in warmer conditions is less is known. Here we compared the effect of early (ELR, after fruit set; diameter of berries $3-5 \mathrm{~mm}$ ) and late (LLR, beginning of veraison) leaf removal on berry composition and wine phenolic profile of grapevine (Vitis vinifera L.) variety Cabernet Sauvignon grown in a temperate, warmer region of Eastern Serbia. Compared to the control (no leaf removal), both leaf removal treatments increased the sugar content in fresh juice and alcohol concentration in wine. Over three consecutive years (2011-2013) markedly different in temperature and rainfall, ELR was clearly most effective in decreasing weights of cluster and of one berry, and in increasing of skin share in a berry. The content of total phenols, tartaric acid esters, anthocyanins, and flavanols in berry skin and wine was the highest in ELR treatment. ELR prominently modified the phenolic profile: Increasing flavanols, myricetin and quercetine in skin and wine, and anthocyanins, peonidin-3-glucoside in skin and delphinidin-3-glucoside in wine. This work demonstrated that early leaf removal positively influenced the chemical composition of berries and wine of Cabernet Sauvignon and might be recommended for practice in the temperate warm conditions.
\end{abstract}

Keywords: anthocyanin; berry skin; canopy management; flavanol; grape yield; wine quality

\section{Introduction}

Cluster zone leaf removal (also termed as defoliation) is one of the most effective canopy management practices for altering microclimatic conditions surrounding the grape cluster (e.g., better aeration and sun light exposure of clusters, decreased humidity) and has shown to improve berry and wine quality $[1,2]$. The canopy leaf area greatly influences the changes in the properties of clusters and berries, such as the contents of sugars, total acids, and colored and aromatic compounds. Accordingly, partial removal of leaves in the cluster zone has been recognized as one of the most important activities in the vineyard. The modification of canopy microclimate and light exposure of clusters by leaf removal in the cluster zone showed the influence on the chemical and organoleptic properties of grapes and wines [3-8]. This effect mainly depends on the degree of leaf biomass removal, and on the timing $[8,9]$. In most vine regions worldwide, leaf removal is usually performed in the period after flowering to the beginning of veraison. Leaf removal from the cluster zone is usually practiced in cooler to moderate climates to increase temperature and light quality in the cluster zone $[8,10]$. However, in the warm climates a removal of leaves in cluster zone, in particular before or during veraison, may cause sunburns and overheating of berries, which lowers the wine quality [11]. In a cooler climate, early leaf removal usually decreases grape yield due to decreased berry size, but in parallel increases components 
of wine quality [12]. However, leaf removal in warmer climates has less been studied. In such climates, early leaf removal and subsequently increased cluster exposure to sun light, although less affecting grape yield, increased berry sugar and phenolics, and maintained must acidity [8], but occasionally led to berry discoloration [13].

Phenolic compounds are very important for the quality of red wines, affecting both organoleptic characteristics and benefits for human health [14]. The content and composition of the phenolic compounds depends on the variety, ecological conditions, and vineyard management. Hunter et al. [5] demonstrated that the concentration of anthocyanins increased with partial defoliation at veraison, while the wine quality was considerably improved by this measure regardless of the timing. Late defoliation (post-veraison and pre-harvest) on Sangiovese increased the total flavanols in berry skin; however, it did affect the total anthocyanins [15]. Moreover, in the same study [15], no significant differences between late defoliation and control (no defoliation) treatments were found for total polyphenols, alcohol, titratable acidity, and $\mathrm{pH}$ in wine.

Most of phenolic compounds, especially anthocyanins, are concentrated in the berry skin. Early leaf removal (after flowering to the berry set stages), for instance, reduced the size and number of berries and increased the skin/flesh ratio, resulting in an increased content of phenolic compounds in wine [16]. It has further been shown that the smaller size of berries was a result of the reduction of the assimilation surface during the flowering and fruit set stages [17]. Leaf removal also resulted in the higher sugar content in must, increased phenolic content in berry skin and more of stable anthocyanins in wine [18,19].

Despite the extensive research in the past decade, the effect of the timing of cluster zone leaf removal for the specific region and rather continental climatic conditions of Eastern Serbia characterized by warm summertime (July-September), is not well understood. It has been hypothesized that the cluster zone leaf removal will significantly influence the quality of both grapes and wine of Cabernet Sauvignon grown in the specific climate conditions of Eastern Serbia. Therefore, the aim of this study is to evaluate the effects of cluster zone leaf removal timing (early and late, compared to no leaf removal) on the quality of Cabernet Sauvignon grapes and wine with special emphasis on the phenolic profile.

\section{Materials and Methods}

\subsection{Vineyard Description}

This research was conducted over three consecutive seasons (2011-2013) on the Vitis vinifera L. cv. Cabernet Sauvignon. The vineyard was planted in 2001 on rootstock $5 B B$, with the 3333 plants per hectare $(3 \times 1 \mathrm{~m})$. The location of vineyard is in Negotinska Krajina wine region, Serbia, South-eastern Europe $\left(44^{\circ} 04^{\prime} 05^{\prime \prime} \mathrm{N}\right.$ and $22^{\circ} 33^{\prime} 26^{\prime \prime} \mathrm{W}$; altitude of $140 \mathrm{~m}$ ). Bud break for Cabernet Sauvignon in this area usually occurs by mid April, flowering by mid June; veraison by early August, with harvest by late September, and leaf fall in November. The climate of the experimental area is temperate mesothermal with hot and humid summers (Köppen class Cfa), characterized by both sub-continental and sub-Mediterranean influences [20]. With average annual precipitation about $570 \mathrm{~mm}$ (of which $54 \%$ is delivered during vegetation period), Lang's rain factor about 45 and de Martonne's aridity index about 24 , the research locality is under semi-arid conditions. Mean annual temperature is $11.8^{\circ} \mathrm{C}$ and average daily temperature from April to September of $19.2^{\circ} \mathrm{C}[21]$.

The vineyard was on a slight slope with the row orientation approximately north-west to south-east. The soil was a Vertisol; $\mathrm{pH}$ (in $1 \mathrm{M} \mathrm{KCl}$ ) $6.07,1.87 \%$ of soil organic matter, $9.7 \mathrm{mg} \mathrm{kg}^{-1}$ soil of ammonium lactate-extractable $\mathrm{P}$ and $80.5 \mathrm{mg} \mathrm{kg}^{-1}$ of exchangeable $\mathrm{K}$; no fertilization/irrigation during the entire experiment were applied. Vine training system was a modified two-arm cordon with a trunk height of $1.4 \mathrm{~m}$. The number of buds retained by pruning was 24 , distributed on two canes with ten buds and two replacement spurs with two buds each. The locally common soil management and fungicides were applied to all the treatments. 


\subsection{Experimental Design}

Leaf removal from the cluster zone was done manually in two period of times: Early leaf removal (ELR) after berry set (diameter of berries 3-5 mm; BBCH 73 growth stage, Lorenz et al., [22] and late leaf removal (LLR) at the beginning of veraison ( $\mathrm{BBCH} 81$ growth stage), with the same intensity (removing 5 fully developed basal leaves per shoot), and no leaf removal in the control. The lateral shoots were retained. The experiment was carried out in a random block design with three blocks and three treatments with 10 plants per treatment in each block.

\subsection{Grape Harvest, Analyses of Grape Juice and Estimation of Vegetative Growth}

At commercial harvest time all clusters per vine were harvested (in the stage of "technological maturity" reached at different dates: 25 September 2011, 15 September 2012 and 28 September 2013). Ten vines were harvested in each replicate (block) per treatment. The clusters were weighted to determine the yield and mean cluster weight. The berries were counted from 30 randomly taken clusters per each replicate. In addition, 50 berries were randomly taken from each sample for weighting and then crushed by fingers in order to remove the skins. The skins were rinsed with tap water to completely separate the pulp and, after which they were blotted with filter paper and weighed. The relative skin share (\%) was calculated following equation: skin weight $\times 100 /$ berry weight. The composite grape samples from 10 vines (each containing $12 \mathrm{~kg}$ ) were divided into two parts; one part (about $2 \mathrm{~kg}$ ) was frozen $\left(-20^{\circ} \mathrm{C}\right.$ ) for further chemical analyses, and the other (about $10 \mathrm{~kg}$ ) was crushed by hand and then subjected to microvinification.

At harvest, total sugar content in the fresh grape juice was determined by portable refractometer (MR200ATC Milwaukee Meters, Neutron Pl Rowville, VIC, Australia) and the titratable acidity (total acid concentration) was determined by titration with $0.1 \mathrm{~N}$ $\mathrm{NaOH}$ to a $\mathrm{pH} 8.2$ end point.

The vine vegetative growth was estimated by measuring pruning weight per vine during the winter period following the growing season.

\subsection{Microvinification}

The must was treated with potassium metabisulfite $\left(0.1 \mathrm{~g} \mathrm{~kg}^{-1}\right)$ and inoculated with the commercial wine yeast (BDX, Lallemand Oenology, Castel dAzzano, Italy) $\left(0.25 \mathrm{~g} \mathrm{~kg}^{-1}\right)$. After 10 days of maceration and primary fermentation in $15 \mathrm{~L}$ plastic pots, the fermenting juice was removed and the skins are pressed by hand to extract the remaining juice. The secondary fermentation was continued in $5 \mathrm{~L}$ glass demijohn for the next 10 days and then treated with $0.05 \mathrm{~g}$ of potassium metabisulfite. After one month wine was transferred to another $5 \mathrm{~L}$ glass demijohn for and after 3 months wine was bottled $(0.75 \mathrm{~L})$ and aged for 6 months prior to analyses.

\subsection{Chemical Analyses of Berry Skin and Wine}

Thirty berries were randomly taken from each frozen sample $(2 \mathrm{~kg}$ collected from 10 vines), the skin was removed by forceps, homogenized in a mortar using liquid nitrogen, and $1 \mathrm{~g}$ of the skin homogenate was taken and mixed with $10 \mathrm{~mL} 50 \%$ methanol in the plastic tubes. Tubes were closed, shaken and left for $60 \mathrm{~min}$ at room temperature, with shaking every $10 \mathrm{~min}$. The supernatants were subjected to further analysis of phenolic compounds.

Total phenols, total tartaric acid esters and total flavanols were determined following the method of Mazza et al. [23]. The samples (skin extract as described above or 6-month bottle aging wine) were mixed with acidified ethanol $(2 \% \mathrm{HCl}$ in $95 \%$ ethanol) in the ratio of $1: 10(\mathrm{v} / \mathrm{v})$, incubated for $15 \mathrm{~min}$ at room temperature, filtered through a membrane filter ( $0.45 \mu \mathrm{m}$ pore size) and measured spectrophotometrically (Agilent $8453 \mathrm{UV}$-VIS Spectrophotometer, Santa Clara, CA, USA) at $280 \mathrm{~nm}$ (total phenols; gallic acid standard), $320 \mathrm{~nm}$ (tartaric acid esters; caffeic acid standard) and $360 \mathrm{~nm}$ (total flavanols; quercetin standard). The concentrations were expressed in $\mathrm{mg}$ standard equivalent per $\mathrm{g}$ of berry skin. 
Total anthocyanins were determined by the modified method of Di Stefano [24]. After 15-min incubation of $0.5 \mathrm{~mL}$ samples (skin extract as described above or 6-month bottle aging wine) in $10 \mathrm{~mL}$ solution containing mixture ethanol:d-water:hydrochloric acid $(70: 29: 1 \mathrm{v} / \mathrm{v} / \mathrm{v})$, the absorbance was measured spectrophotometrically (Agilent $8453 \mathrm{UV}$ VIS Spectrophotometer, Santa Clara, CA, USA) at $520 \mathrm{~nm}$, and the total anthocyanins were expressed as malvidin-3-glucoside per $\mathrm{g}$ of berry skin.

In addition, the individual phenolic compounds (flavanols and anthocyanins) were determined in the berry skin and wine samples from the year 2012, which happened to be rather typical for the Eastern Serbia terroir (see Table 1 and Supplementary Table S7). The profile of flavanols (e.g., malvidin-3-glucoside, peonidin-3-glucoside, petunid-3-glucoside, cyanidin-3-glucoside and delphidin-3-glucoside) and anthocyanins (e.g., quercetin-glucoside, quercetin, rutin, morin, myricetin, and kaempferol) was determined by the high-performance liquid chromatography (HPLC, Agilent Technologies 1200, Santa Clara, CA, USA) with diode array detector (DAD), whereas the catechin was determined by HPLC with fluorescence detector $(275-322 \mathrm{~nm})$. Prior to the HPLC analysis, the extracts were further filtered through membrane filters with a pore size of $0.45 \mu \mathrm{m}$. Separation was carried out on the column Agilent-Eclipse XDB C-18 $4.6 \times 150 \mathrm{~mm}$; the column was calibrated at $30^{\circ} \mathrm{C}$; the solvents were: Formic acid:water (5:95 v/v) - solvent A, and acetonitrile:formic acid:water $(80: 5: 15 \mathrm{v} / \mathrm{v})-$ solvent $\mathrm{B}$. The linear elution gradient was used as follows: From 0 to $10 \mathrm{~min}$, $0.0 \% \mathrm{~B}, 10$ to $28 \mathrm{~min}, 10.0 \% \mathrm{~B}, 28$ to $35 \mathrm{~min}, 25 \% \mathrm{~B}, 35$ to $40 \mathrm{~min}, 50 \% \mathrm{~B}, 40$ to $45 \mathrm{~min}, 80 \%$ $\mathrm{B}$ and for the last $10 \mathrm{~min}$ again $0 \% \mathrm{~B}$. The injection volume was $5 \mu \mathrm{L}$ and the flow of the

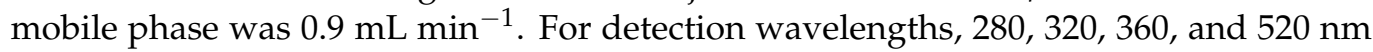
for DAD were selected, and $275 / 322 \mathrm{~nm}\left(\lambda_{\mathrm{Ex}} / \lambda_{\mathrm{Em}}\right)$ for fluorescent detection. Different phenolic compounds were identified by comparing their retention times and spectral characteristics with the data of original standard components. Quantification was performed using external calibration with the standards of phenolic compounds (HPLC-grade, $\geq 98 \%$, Sigma-Aldrich, St. Louis, MO, USA). The calibration curves were linear, with the coefficient of determination $\mathrm{R}^{2}=0.99$.

Table 1. The selected weather parameters of the experimental years (2011-2013). Growing degree days (GDD; base $10^{\circ} \mathrm{C}$ ), rainfall registered during the bud burst to harvest period, annual rainfall, insolation and average daily maximum air temperature (AMDT) during the veraison to harvest period for Cabernet Sauvignon (August-September).

\begin{tabular}{cccc}
\hline Parameter $^{\mathbf{1}}$ & $\mathbf{2 0 1 1}$ & $\mathbf{2 0 1 2}$ & $\mathbf{2 0 1 3}$ \\
\hline Growing degree days (GDD) $^{-19}$ & 1784 & 1976 & 1686 \\
Average daily maximum air temperature (AMDT) $\left({ }^{\circ} \mathrm{C}\right)$ & 30.3 & 32.1 & 28.9 \\
Insolation June-September (h) & 1951 & 2009 & 1872 \\
Rainfall April-September (mm) & 148 & 239 & 280 \\
Annual rainfall (mm) & 352 & 533 & 700 \\
\hline
\end{tabular}

${ }^{1}$ Data from the Republic Hydrometeorological Service of Serbia (http:/ / www.hidmet.gov.rs).

Alcohol in the wine samples was determined using pycnometer method. The titratable acidity (total acid concentration) in wine was determined by titration with $0.1 \mathrm{~N} \mathrm{NaOH}$ to a phenolphthalein end point. Volatile acidity in wines was determined by distillation using a Cazenave-Ferré followed by titration with phenolphthalein.

\subsection{Statistical Analysis}

The data were statistically analyzed by the 2-way ANOVA model with interaction term, after normality of residuals and homoscedasticity tests. The two treatments were leaf removal (control-no leaf removal, late leaf removal, and early leaf removal), and growth season (i.e., experimental year: 2011, 2012, and 2013). The significance of the differences between treatment means were analyzed by Tukey's Honestly significant test, using a conventional level of significance of $5 \%(\alpha=0.05)$. Analyses of variance were performed by the STATISTICA 6 software (StatSoft Inc., Tulsa, OK, USA). 
The multivariate structure of the collected data was visualized by Principal Component Analysis (PCA) by PC-ORD 6 software (MjM Software Design, Gleneden Beach, OR, USA), using correlation cross-product matrix, Euclidean distance and no rotation. Correlation cross-product matrix was centered and standardized (relativized by standard deviate), what brought all the analyzed variables to an equal footing. The differences among the chemical profiles of skin and wine, induced by the leaf removal treatment, were analyzed by Multi-Response Permutation Procedure (MRPP; Mielke and Berry [25]). This is a nonparametric procedure for testing the hypothesis of no difference between pre-defined groups; data were relativized by standard deviate to bring all the variables to the same footing prior to analyses and be in accordance with the PCA.

\section{Results and Discussion}

\subsection{Vine Growth and Grape Yield}

Vine vegetative growth, grape yield and yield components were differently affected by leaf removal treatment and experimental year (Table 2, Supplementary Table S1). Figure 1 shows the main effect of a factor with the strongest influence on each measured parameter (after ANOVA analysis, Supplementary Table S1). Overall, pruning weight (Figure 1a), grape yield (Figure 1b), and number of clusters per vine (Figure 1c) were strongly modified by experimental year and the highest in 2013, which was incidentally unusually moist year (Table 1; see also Supplementary Table S7). Vegetative growth (expressed as pruning weight per plant) and number of clusters per vine were even not affected by leaf removal treatment (Table 2, Supplementary Table S1). Compared to other years, pruning weight per vine was on average by $37 \%$ higher in the year with the highest amount of precipitation (2013-see Table 1), Figure 1a). Grape yield ranged from $1.99 \mathrm{~kg}$ (ELR treatment in 2012) to $5.08 \mathrm{~kg}$ (LLR treatment in 2013) (Table 2). Across all the canopy management strategies evaluated (no leaf removal, early, and late leaf removal), the grape yield was in 2012 by $43 \%$ lower compared to the year 2013, and by $21 \%$ lower compared to the year 2011. However, across the three growth seasons, the average grape yield was the lowest in ELR treatment ( $3.34 \pm 1.14 \mathrm{~kg}$ per vine); it decreased by $9 \%$ in comparison with the LLR treatment, and by $17 \%$ compared to the control. The number of clusters per vine (Figure 1c) followed the same pattern as grape yield; it was the highest in 2013, and decreased by 73\% in 2012 .

Table 2. Effects of leaf removal time and experimental year on the vegetative growth and yield components of Cabernet Sauvignon. LLR, late leaf removal; ELR, early leaf removal. Data are means of three replicates \pm sd. Different letters in a column denote significant differences among treatments according to Tukey's test following a two-way ANOVA at $\alpha=0.05$.

\begin{tabular}{|c|c|c|c|c|c|c|c|}
\hline $\begin{array}{c}\text { Experimental } \\
\text { Year }\end{array}$ & Treatment & $\begin{array}{l}\text { Pruning Weight } \\
\left.\text { (kg Vine }^{-1}\right)\end{array}$ & $\begin{array}{l}\text { Grape Yield } \\
\left(\text { kg Vine }^{-1}\right)\end{array}$ & $\begin{array}{l}\text { Clusters } \\
\text { per Vine }\end{array}$ & $\begin{array}{c}\text { Cluster } \\
\text { Weight (g) }\end{array}$ & $\begin{array}{l}\text { Berries Weight } \\
\text { (g Cluster }^{-1} \text { ) }\end{array}$ & $\begin{array}{l}\text { One Berry } \\
\text { Weight (g) }\end{array}$ \\
\hline \multirow{4}{*}{2011} & Control & $1230 \pm 27^{a}$ & $4.0 \pm 0.4^{\mathrm{cd}}$ & $36 \pm 2^{b}$ & $114 \pm 3^{b c}$ & $110 \pm 3^{d}$ & $1.02 \pm 0.01^{b}$ \\
\hline & LLR & $1089 \pm 46^{\mathrm{a}}$ & $2.9 \pm 0.1^{b}$ & $27 \pm 2^{a}$ & $106 \pm 6^{b c}$ & $101 \pm 6^{b c d}$ & $1.00 \pm 0.03^{b}$ \\
\hline & ELR & $1177 \pm 65^{\mathrm{a}}$ & $3.5 \pm 0.4^{b c}$ & $35 \pm 2^{b}$ & $100 \pm 13^{b c}$ & $96 \pm 13^{b c}$ & $0.81 \pm 0.04^{\mathrm{a}}$ \\
\hline & Control & $1212 \pm 15^{\mathrm{a}}$ & $3.2 \pm 0.1^{b}$ & $26 \pm 2^{a}$ & $117 \pm 7^{d}$ & $113 \pm 7 \mathrm{bcd}$ & $1.02 \pm 0.02^{b}$ \\
\hline \multirow[t]{2}{*}{2012} & LLR & $1141 \pm 52^{\mathrm{a}}$ & $3.1 \pm 0.2^{b}$ & $27 \pm 2^{a}$ & $115 \pm 6^{\mathrm{bc}}$ & $111 \pm 6^{\mathrm{cd}}$ & $1.0 \pm 0.1^{b}$ \\
\hline & ELR & $1173 \pm 72^{a}$ & $2.0 \pm 0.1^{\mathrm{a}}$ & $27 \pm 2^{a}$ & $76 \pm 1^{a}$ & $73 \pm 0.9^{a}$ & $0.80 \pm 0.02^{a}$ \\
\hline \multirow{3}{*}{2013} & Control & $1576 \pm 73^{b c}$ & $4.9 \pm 0.3^{\mathrm{e}}$ & $46 \pm 3^{c}$ & $107 \pm 4^{\mathrm{bc}}$ & $103 \pm 4^{\mathrm{bcd}}$ & $1.07 \pm 0.02^{b}$ \\
\hline & LLR & $1698 \pm 31^{c}$ & $5.1 \pm 0.3^{\mathrm{e}}$ & $47 \pm 4^{\mathrm{c}}$ & $108 \pm 4^{\mathrm{bc}}$ & $104 \pm 4^{\mathrm{bcd}}$ & $1.04 \pm 0.02^{b}$ \\
\hline & ELR & $1526 \pm 89^{b}$ & $4.5 \pm 0.1^{\text {de }}$ & $46 \pm 3^{c}$ & $97 \pm 10^{b}$ & $93 \pm 10^{b}$ & $0.9 \pm 0.1^{\mathrm{a}}$ \\
\hline
\end{tabular}


Experimental year affects pruning weight Current effect: $F(2,18)=206.90, \quad p=0.00$.
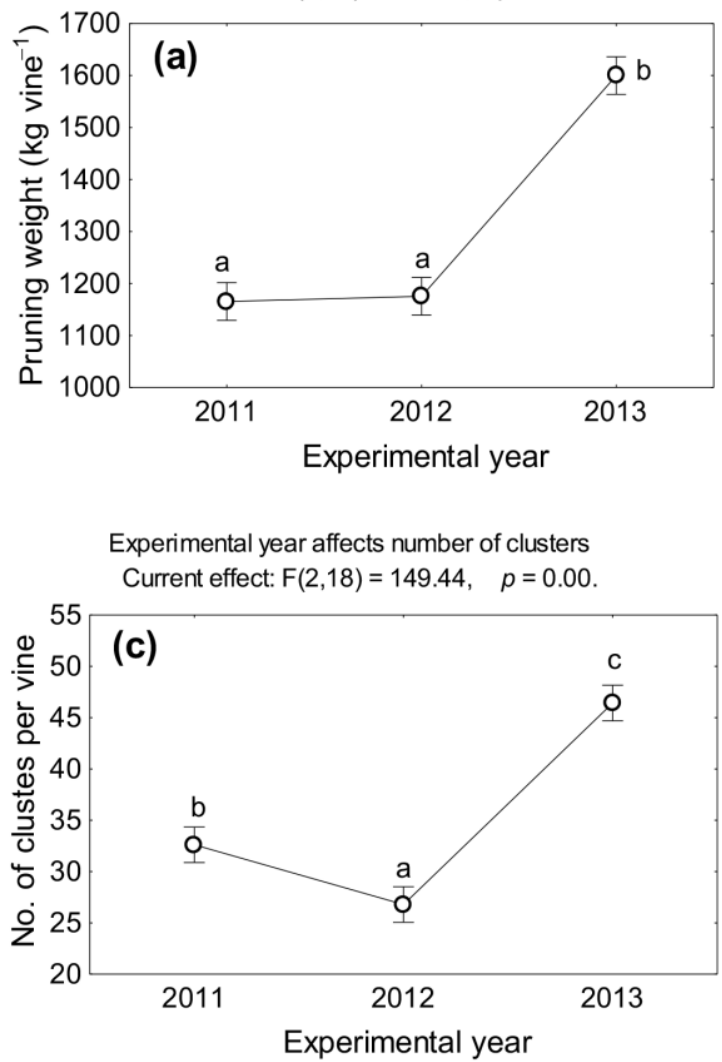

Timing of leaf removal affects weight of berries per cluster Current effect: $F(2,18)=32.16, \quad p=0.00$.

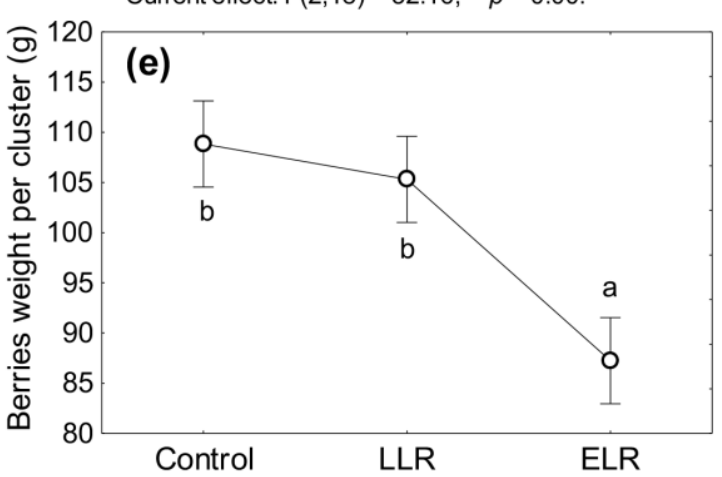

Experimental year affects grape yield Current effect: $\mathrm{F}(2,18)=155.40, \quad p=0.00$

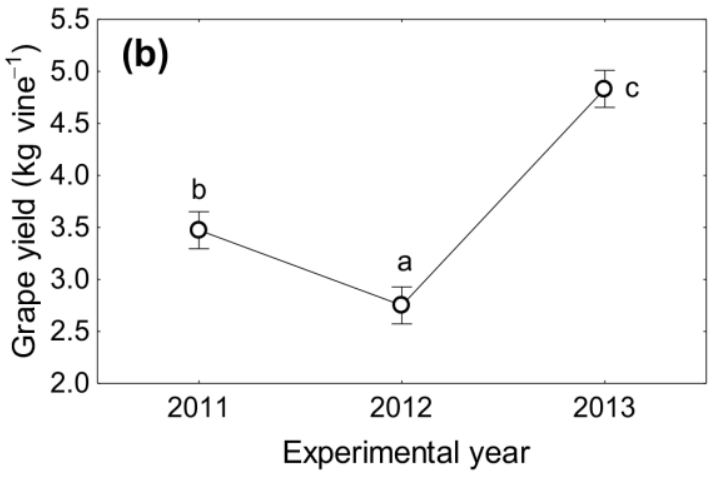

Timing of leaf removal affects cluster weight Current effect: $F(2,18)=32.40, \quad p=0.00$.

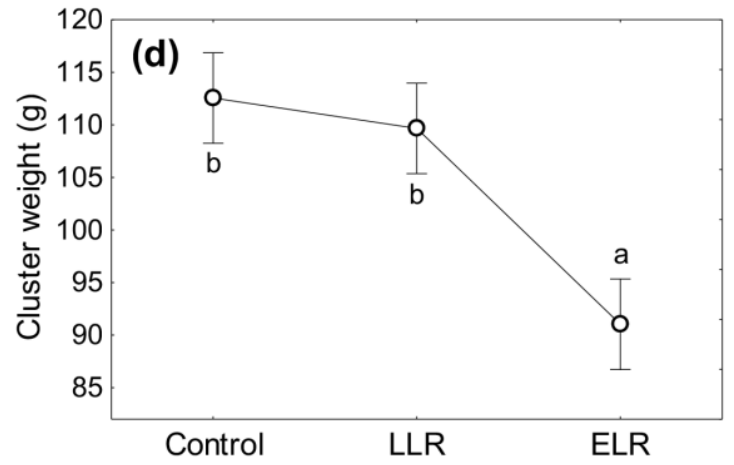

Time of leaf removal affects one berry weight Current effect: $F(2,18)=172.26, \quad p=0.00$.

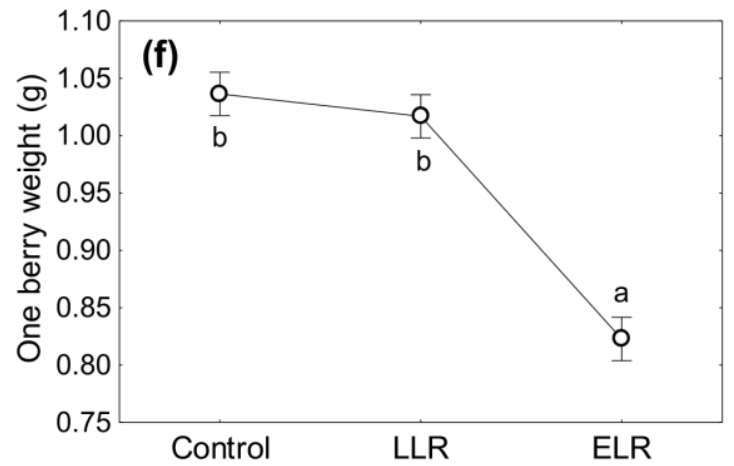

Figure 1. Effect of leaf removal and experimental year on the on the vegetative growth and yield components. (a) pruning weight (full model $\mathrm{R}^{2}$ adj. 0.94, $\mathrm{F}=55.7, p=0.000000$ ); (b) grape yield (full model $\mathrm{R}^{2}$ adj. 0.96, $\mathrm{F}=29.4, p=0.000000$ ); (c) number of clusters per vine (full model $\mathrm{R}^{2}$ adj. 0.92, $\mathrm{F}=40.2, p=0.000000$ ); (d) cluster weight (full model $\mathrm{R}^{2}$ adj. 0.78, $\mathrm{F}=12.5, p=0.000006$ ); (e) weight of berries per cluster (full model $\mathrm{R}^{2}$ adj.0.77, $\mathrm{F}=12.2, p=0.000007$ ); (f) weight of one berry (full model $\mathrm{R}^{2}$ adj. 0.93, $\mathrm{F}=45.0, p=0.000000$ ). Mean values marked with the same letter are not significantly different at $\alpha=0.05$. Vertical bars denote $95 \%$ confidence intervals.

The weight of clusters (Figure 1d), weight of berries in a cluster (Figure 1e), and weight of one berry (Figure 1e) were decisively influenced by canopy management practices, i.e., by leaf removal (Supplementary Table S1). For the weight of clusters and weight of berries per cluster, main effect of growth season could not even be detected. These three parameters were the lowest in ELR treatments (see also Table 2). In particular, the weight of a single berry in vines subjected to early leaf removal was consistently the lowest (compared to control and LLR treatments) in each experimental year (Table 2). Across three years, these three parameters did not differ between control and LLR. The ELR treatment however 
reduced cluster weight by $18 \%$, weight of berries by $23 \%$, and weight of one berry by $20 \%$ in comparison to the averages in control and late removal treatments (Figure 2).
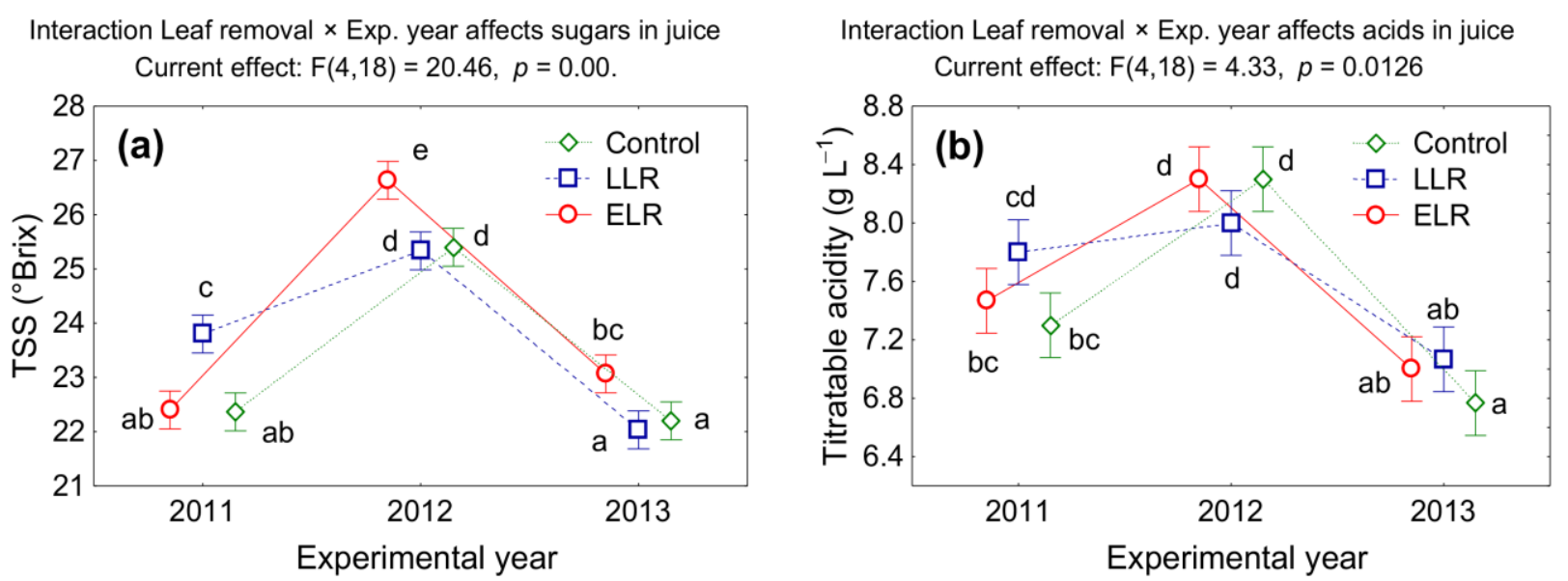

Figure 2. Effect of leaf removal and experimental year on the quality parameters of grape juice. (a) Concentration of sugars (total soluble solids (TSS)) (full model $\mathrm{R}^{2}$ adj. 0.99, $\mathrm{F}=104.3, p=0.000000$ ); (b) concentration of titratable acidity (full model $\mathrm{R}^{2}$ adj. 0.96, $\left.\mathrm{F}=29.4, p=0.000000\right)$. Mean values marked with the same letter are not significantly different at $\alpha=0.05$. Vertical bars denote $95 \%$ confidence intervals.

With an exception for the year 2011 (which was, incidentally, a very dry one; see Table 1), the results for the other two years suggest that the ELR treatment might be an efficient practice in controlling the yield. Since the yield depends on several factors, such as number of berries and weight and number of clusters, the lower ELR yield in the experiment is probably due to the lower average weight of clusters and berries compared to control and LLR treatments. Present results are in agreement with the results of various studies which reported that early leaf removal (flowering and berry set) is an effective measure in controlling the yield in different climate conditions $[9,26-28]$. A lower grape yield recorded in ELR treatment was mainly caused by a decreased berry weigh, and thereby weight of clusters (Table 2; Figure 1), which is in accordance with the results of Moreno et al. [26] in Tempranillo grown in a temperate warm vineyard similar to ours (see Table 1 in this study and Table 1 in the study of Moreno et al.). However, Bledsoe et al. [29] reported that defoliation did not affect grape yield components and composition (with exception of an increased TSS in the early leaf removal treatment) of Sauvignon Blanc grown in the climate conditions of Napa (California), with more robust training system and lower vine density than in the present study.

\subsection{General Quality Parameters of Gape Juice and Wine}

Experimental year exhibited the strongest effect on both total sugar content (Figure 2a) and titratable acidity (Figure 2b) in fresh grape juice (see Supplementary Table S2). The tested canopy management practices, furthermore, did not show any statistically significant effect on the total acidity of grape juice (Supplementary Table S2). On average, across three leaf removal treatments, sugar content (expressed as TSS) in 2012 was by $12 \%$ and 15\% higher than in 2011 and 2013, respectively. This increase in sugar content in the year 2012 was most prominent in ELR treatment (Figure 2a), which is in agreement with findings of Moreno et al. [26]. Likewise, total juice acidity across all the leaf removal treatments in 2012 (on average $8.2 \mathrm{~g} \mathrm{~L}^{-1}$ ) was by $9 \%$ and by $18 \%$ higher than in 2011 and 2013 , respectively. Furthermore, across three different growth seasons, TSS in juice was the lowest in the control, and did not significantly differ among the two leaf removal timings. Incidentally, the year 2012 happened to be very favorable for grapevine, with the highest temperatures and insolation, and no drought stress (Table 1). Also, in Tempranillo grown in La Rioja (Spain), basal leaf removal at fruit setting stage led to more ripened grape berries 
in terms of higher TSS and decreased acidity [30]. However, very recent study on Cabernet Sauvignon grown in the North Serbia terroir showed that early leaf removal decreased total acidity of grape juice, but did not affect TSS [31].

Consistently with the sugars and acids in fresh berry juice (Figure 2), the experimental year exhibited the strongest influence also on quality parameters in wine (Figure 3; Supplementary Table S3). Nevertheless, it has been shown that wine quality might not always be simply a function of TSS and berry acidity [8]. Alcohol concentration in wine was the highest in the year 2012, and in particular in the in ELR treatment (15.7\%, Figure 3a). In an apparently most favorable year for wine (2012), alcohol concentration in wine was by $24 \%$ higher than in other two experimental years. On average, across three years of the experiment, the concentration of alcohol in wine was the lowest in the control treatments (no leaf removal, Figure 3a). The years 2011 and 2013 conspicuously differed in the rainfall (2011 was rather dry, and 2013 rather humid; Table 1, Supplementary Table S7). and what coincided with a prominent difference in pruning weight, grape yield and number of clusters (Figure 1a-c). Yet no differences between these non-optimal years was observed for the TSS in fresh juice (Figure 2a) nor for the alcohol in wine (Figure 3a). Furthermore, LLR treatment caused, on average across the experimental years, a small, but statistically significant increase of titratable acidity in wine by $4 \%$ compared to ELR, and by $7 \%$ compared to the control treatments (Figure $3 \mathrm{~b}$ ). In contrast to our findings, wine parameters such as alcohol content and titratable acidity were unaffected by defoliation of Grenache vines grown in La Rioja terroir, although early leaf removal positively affected wine color and sensory parameters [27]. On the other hand, the experimental year did not markedly change the pattern of how the volatile acidity in wine were affected by leaf removal (Figure 3c). Volatile acids in wine were, across the three experimental years, by up to $30 \%$ lower in control, then in the treatments involving leaf removal (Figure $3 \mathrm{c}$ ). These results are in agreement with the findings that wine from shaded clusters of Shiraz showed significantly lower alcohol content, total and titratable acidity [32].

\subsection{Polyphenolic Composition of Grape Berry Skin and Wine}

Interestingly, across three consecutive experimental years markedly differing in precipitation and temperature (Table 1), ELR treatment had a clear, consistently favorable effect on polyphenolic composition of berry and wine. For instance, leaf removal treatment was the strongest modifier of a proportion of skin in a fresh berry (Supplementary Table S4). Share of skin was in fact the only parameter measured in this study not affected by leaf removal $x$ experimental year interaction. In this study, ELR treatment resulted in the highest skin proportion in grape berry in all the experimental years, while there was no difference between LLR and control treatments (Figure 4). Across the three experimental years, average skin share of $6.71 \%$ in ELR treatment was 1.14-fold and 1.20-fold higher than in LLR and control treatments, respectively. Early leaf removal (before or after flowering) may also induce a so-called "photosynthetic shock" i.e., reduced overall photosynthetic activity of grapevines, which in turn may cause a reduced influx of assimilates from leaves to blossoms or newly formed clusters and consequently formation of the smaller berries with an increased skin-to-flesh ratio [30,31]. Excessive sunlight exposure of clusters due to an intensive leaf removal, together with high cluster temperature also resulted in smaller berries comparing with those in the shade [13,32]. Increased percentage of the skin (Figure 4) in smaller berries (Figure 1f) was associated with the increased content of phenolic compounds in berry skin (Table 3), especially anthocyanins whose synthesis occurs in the grape berry skin. Reduced mesocarp (flesh) and increased proportion of the skin is crucial for the quality of the wine, since the phenolics from the skin are extracted during the maceration process $[17,31]$. The highest proportion of the skin in the berry mass (ELR treatment, Figure 4) consequently reflected the highest content of the phenolic compounds in the ELR wine, extracted during the maceration process in each of the three experimental years (Table 4). 
Interaction Leaf removal $\times$ Exp. year affects alcohol in wine

Current effect: $F(4,18)=90.62, p=0.00$.

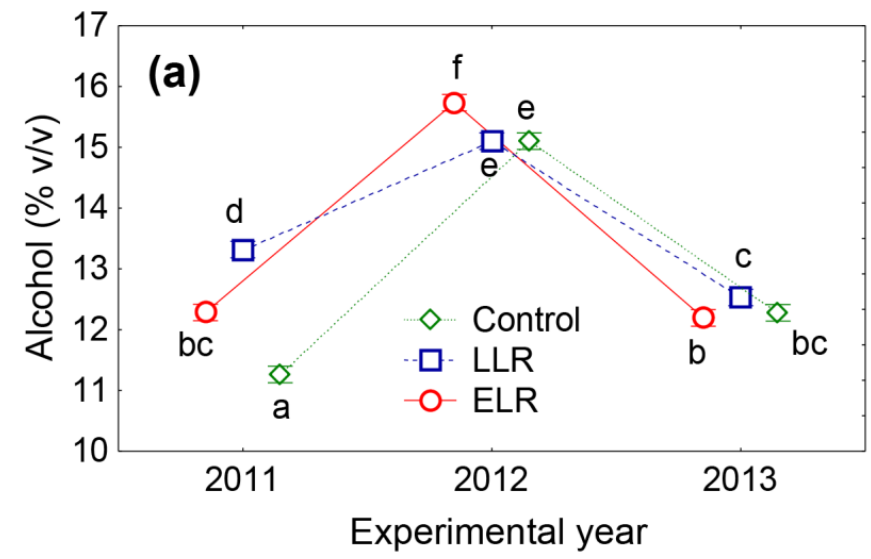

Interaction Leaf removal $\times$ Exp. year affects total acids in wine Current effect: $F(4,18)=5.14, p=0.0061$

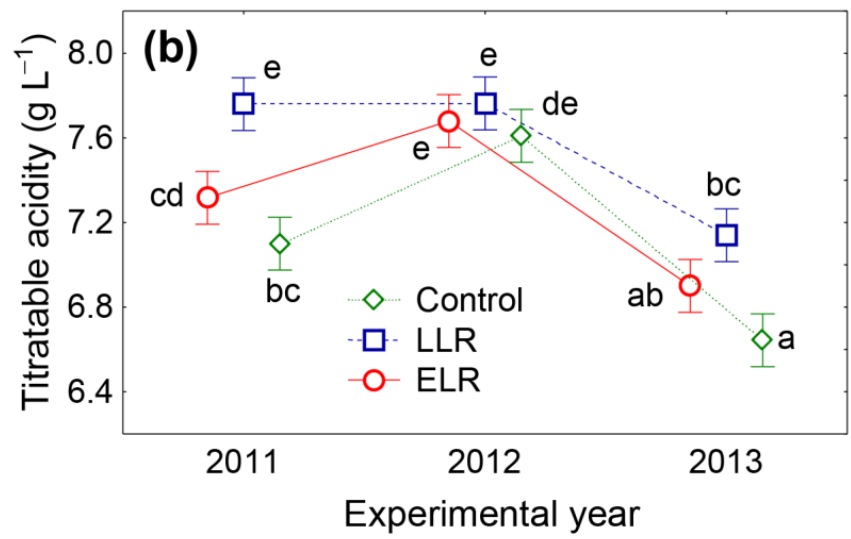

Leaf removal affects volatile acids in wine Leaf removal $\times$ Exp. year: $F(4,18)=8.33, p=0.00055$

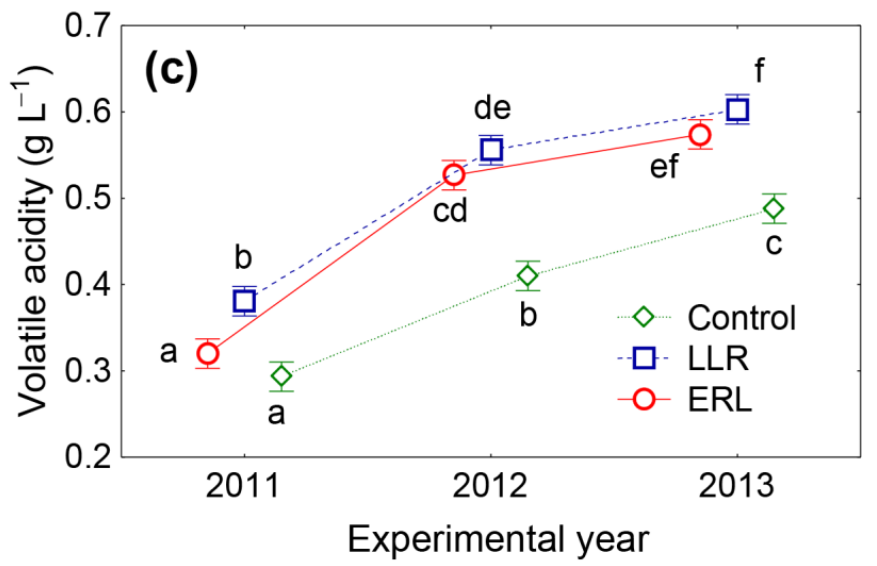

Figure 3. Effect of leaf removal end experimental year on the quality parameters of wine (after 6 months of aging). (a) Concentration of alcohol (full model $\mathrm{R}^{2}$ adj. 0.998, $\mathrm{F}=612.9, p=0.000$ ); (b) concentration of total acids (full model $\mathrm{R}^{2}$ adj. 0.98, $\mathrm{F}=46.6, p=0.000000$ ); (c) concentration of volatile acids (full model $\mathrm{R}^{2}$ adj. 0.98, $\mathrm{F}=198.0, p=0.000000$ ). Mean values marked with the same letter are not significantly different at $\alpha=0.05$. Vertical bars denote $95 \%$ confidence intervals. 
Interaction Leaf removal $\times$ Exp. year does not affect skin share

Current effect: $F(4,18)=1.29, p=0.312$

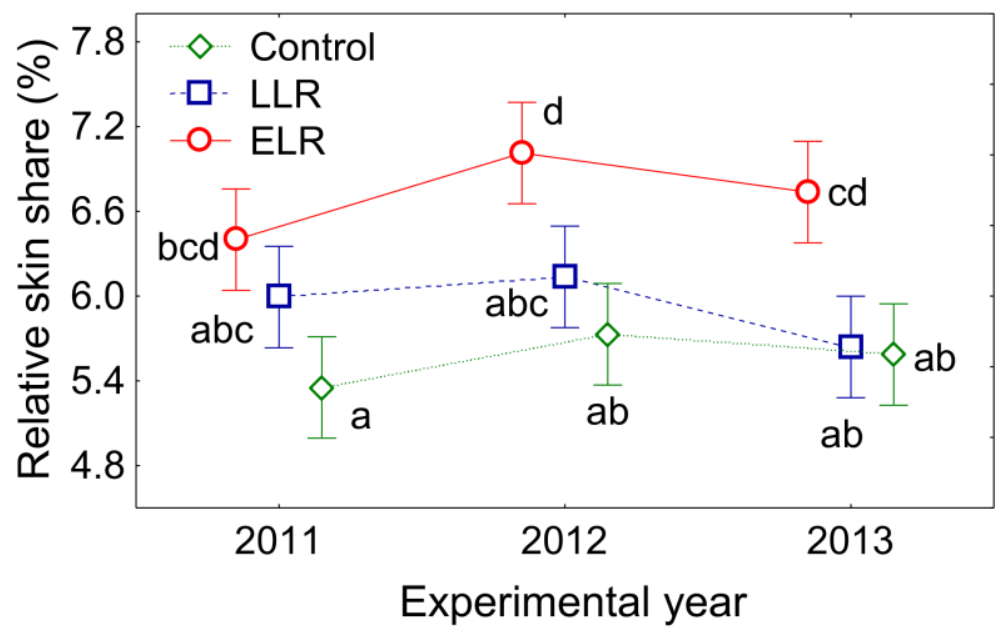

Figure 4. Effect of leaf removal and experimental year on the relative proportion of skin in a grape berry. Full model $\mathrm{R}^{2}$ adj. $0.75, \mathrm{~F}=10.7, p=0.000019$. Mean values marked with the same letter are not significantly different at $\alpha=0.05$. Vertical bars denote $95 \%$ confidence intervals.

Table 3. Effects of leaf removal time and experimental year on the concentrations of total phenols, tartaric acid esters, and anthocyanins and flavanols in berry skin determined by HPLC. LLR, late leaf removal; ELR, early leaf removal. Data are means of three replicates $\pm \mathrm{sd}$. Different letters in a column denote significant differences among treatments according to Tukey's test following a two-way ANOVA at $\alpha=0.05$.

\begin{tabular}{|c|c|c|c|c|c|}
\hline $\begin{array}{l}\text { Experimental } \\
\text { Year }\end{array}$ & Treatment & $\begin{array}{l}\text { Total Phenols } \\
\left(\mathrm{mg} \mathrm{g}^{-1} \text { FW) }\right.\end{array}$ & $\begin{array}{l}\text { Total Tartaric Acid Esters } \\
\qquad\left(\mathrm{mg} \mathrm{g}^{-1} \text { FW) }\right.\end{array}$ & $\begin{array}{l}\text { Total Anthocyanins } \\
\quad\left(\mathrm{mg} \mathrm{g}^{-1} \mathrm{FW}\right)\end{array}$ & $\begin{array}{l}\text { Total Flavonols } \\
\left(\mathrm{mg} \mathrm{g}^{-1} \text { FW) }\right.\end{array}$ \\
\hline \multirow{4}{*}{2011} & Control & $12.67 \pm 0.05^{\mathrm{c}}$ & $1.371 \pm 0.008^{a}$ & $0.172 \pm 0.007^{a}$ & $1.469 \pm 0.006^{b}$ \\
\hline & LLR & $16.69 \pm 0.04^{g}$ & $3.91 \pm 0.04^{\mathrm{e}}$ & $0.173 \pm 0.004^{\mathrm{a}}$ & $3.3 \pm 0.03^{f}$ \\
\hline & ELR & $18.79 \pm 0.07^{\mathrm{i}}$ & $4.30 \pm 0.04^{\mathrm{d}}$ & $0.199 \pm 0.009^{b}$ & $4.14 \pm 0.03^{h}$ \\
\hline & Control & $17.728 \pm 0.04^{\mathrm{h}}$ & $4.09 \pm 0.02^{\mathrm{cd}}$ & $0.286 \pm 0.009^{f}$ & $1.466 \pm 0.003^{b}$ \\
\hline \multirow[t]{2}{*}{2012} & LLR & $9.438 \pm 0.008^{a}$ & $1.34 \pm 0.01^{\mathrm{a}}$ & $0.206 \pm 0.003 b c$ & $3.185 \pm 0.005^{\mathrm{e}}$ \\
\hline & ELR & $15.468 \pm 0.008^{f}$ & $3.721 \pm 0.007^{c}$ & $0.252 \pm 0.003^{\mathrm{e}}$ & $3.97 \pm 0.03 \mathrm{~g}$ \\
\hline \multirow{3}{*}{2013} & Control & $11.654 \pm 0.001^{b}$ & $1.363 \pm 0.001^{\mathrm{a}}$ & $0.197 \pm 0.003^{b}$ & $1.09 \pm 0.01^{\mathrm{a}}$ \\
\hline & LLR & $14.43 \pm 0.03^{\mathrm{d}}$ & $2.88 \pm 0.01^{b}$ & $0.217 \pm 0.004^{\mathrm{cd}}$ & $2.717 \pm 0.004^{c}$ \\
\hline & ELR & $14.8 \pm 0.2^{\mathrm{e}}$ & $2.9 \pm 0.6^{b}$ & $0.22 \pm 0.01^{\mathrm{d}}$ & $3.01 \pm 0.02^{\mathrm{d}}$ \\
\hline
\end{tabular}

Table 4. Effects of leaf removal time and experimental year on the concentrations of total phenols, tartaric acid esters, and anthocyanins and flavanols in wine (after 6 months of aging) determined by HPLC. LLR, late leaf removal; ELR, early leaf removal. Data are means of three replicates $\pm \mathrm{sd}$. Different letters in a column denote significant differences among treatments according to Tukey's test following a two-way ANOVA at $\alpha=0.05$.

\begin{tabular}{|c|c|c|c|c|c|}
\hline $\begin{array}{l}\text { Experimental } \\
\text { Year }\end{array}$ & Treatment & $\begin{array}{l}\text { Total Phenols } \\
\quad\left(\mathrm{mg} \mathrm{L}^{-1}\right)\end{array}$ & $\begin{array}{l}\text { Total Tartaric Acid Esters } \\
\qquad\left(\mathrm{mg} \mathrm{L}^{-1}\right)\end{array}$ & $\begin{array}{l}\text { Total Anthocyanins } \\
\left(\mathrm{mg} \mathrm{L}^{-1}\right)\end{array}$ & $\begin{array}{l}\text { Total Flavonols } \\
\left(\mathrm{mg} \mathrm{L}^{-1}\right)\end{array}$ \\
\hline \multirow{4}{*}{2011} & Control & $1541 \pm 1^{\mathrm{c}}$ & $322.4 \pm 0.7^{c}$ & $11.0 \pm 0.2^{\mathrm{a}}$ & $178.6 \pm 0.4^{b}$ \\
\hline & LLR & $1984 \pm 1^{g}$ & $422.8 \pm 0.8^{h}$ & $11.2 \pm 0.8^{\mathrm{a}}$ & $291 \pm 1^{\mathrm{g}}$ \\
\hline & ELR & $2113 \pm 115^{h}$ & $522.8 \pm 0.9^{\mathrm{i}}$ & $17.4 \pm 0.4^{b}$ & $417.1 \pm 0.4^{\mathrm{i}}$ \\
\hline & Control & $1147.9 \pm 0.2^{a}$ & $272.7 \pm 0.3^{\mathrm{a}}$ & $16.4 \pm 0.4^{b}$ & $147.7 \pm 0.4^{\mathrm{a}}$ \\
\hline \multirow[t]{2}{*}{2012} & LLR & $1648.2 \pm 0.9^{\mathrm{d}}$ & $338.7 \pm 0.5^{\mathrm{e}}$ & $24.7 \pm 0.4^{\mathrm{d}}$ & $278.7 \pm 0.5^{\mathrm{e}}$ \\
\hline & ELR & $1802 \pm 1^{\mathrm{e}}$ & $381.8 \pm 0.9^{g}$ & $33.2 \pm 0.3^{\mathrm{e}}$ & $306 \pm 0.4^{\mathrm{h}}$ \\
\hline \multirow{3}{*}{2013} & Control & $1366 \pm 1^{b}$ & $328.1 \pm 0.3^{\mathrm{d}}$ & $21.6 \pm 0.5^{\mathrm{c}}$ & $238.4 \pm 0.7^{c}$ \\
\hline & LLR & $1363.8 \pm 0.4^{b}$ & $317.5 \pm 0.5^{b}$ & $21.2 \pm 0.4^{\mathrm{c}}$ & $257.1 \pm 0.4^{\mathrm{d}}$ \\
\hline & ELR & $1855.4 \pm 0.8^{f}$ & $368.6 \pm 0.4^{\mathrm{f}}$ & $21.8 \pm 0.2^{c}$ & $283.2 \pm 0.4^{\mathrm{f}}$ \\
\hline
\end{tabular}


In the present study on Cabernet Sauvignon, both leaf removal times changed the phenolic composition of the berry skin (Table 3 and Figure 5a) and wine (Table 4 and Figure $5 b$ ) in comparison to the control (no leaf removal). In berry skin, the influence of statistical interaction of leaf removal $x$ experimental year (Supplementary Table S5) strongly modified the four analyzed parameters (Table 3). This interaction had the strongest influence on tartaric acid esters, and the weakest on anthocyanins. The simple main effect for year (across three leaf removal treatments) resulted in the highest content of skin total phenols, tartaric acid esters and flavanols in 2011 and the lowest in 2013, while anthocyanins were the highest in 2012. The simple main effect of defoliation clearly showed a superior effect of ELR on the increase of these parameters, while the differences between LLR and control were inconsistent. On the contrary, leaf removal treatment was the strongest modifier of the concentrations of total phenols and flavanols, and tartaric acid esters in wine (Supplementary Table S6). Only the concentrations of total anthocyanins both in berry skin and in wine were decisively under the strongest influence of the characteristics of the growth season (Supplementary Tables S5 and S6).
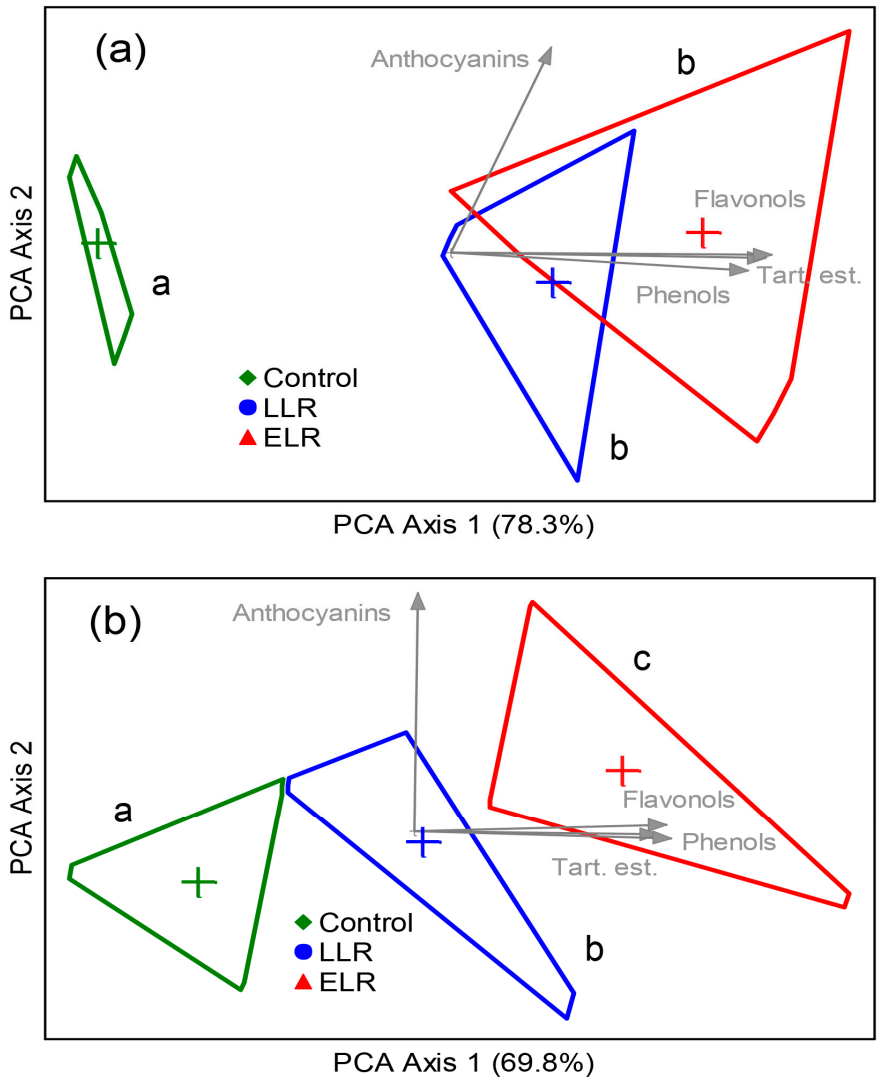

Figure 5. Major gradients (PCA ordination) in the concentrations of four major types of chemical compounds determined by HPLC in the berry skin (a) and the wine (after 6 months of aging) (b) of Cabernet Sauvignon across the three treatments: Control (no leaf removal); LLR (late leaf removal) and ELR (early leaf removal). The values in parenthesis denote the proportion of variance represented by a statistically significant PCA axis. The angles and lengths of the radiating lines indicate the direction and strength of relationships of the variables with the ordination scores. Data matrix: 27 samples collected over three consecutive years (2011-2013), 4 measured variables, correlation cross-product matrix, Euclidean distance, no rotation. Group centroids (crosses) show the average position of a sample within each treatment. Convex hulls (polygons) encompass all the samples in each treatment. Different letters denote that biochemical fingerprints of the leaf removal treatments, as characterized by the 4 measured variables, are statistically different according to the MRPP test, $p<0.05$. All the variables were correlated with the ordination scores by $>35 \%$. 
Despite a strong modifying influence of the experimental year on the effect of leaf removal on skin concentrations of total phenols, tartaric acid esters, flavanols and in particular on anthocyanins and (Table 3, Supplementary Table S5), a general pattern of their increase (across all experimental years) is indicated along the gradient from control, over LLR, to ELR (Figure 5a). Moreover, if these four chemical compounds are used as "fingerprints" to characterize the effect of treatment, treatments involving defoliation are significantly different (by higher concentrations) from the control treatment, with exception of anthocyanins which were more influenced by year and uncorrelated with the main gradient (along the PCA Axis 1, Figure 5). This is in agreement with Moreno et al. [26] in Tempranillo grown in semiarid conditions of Western Spain. These authors reported that early leaf removal did not significantly change the concentration of total anthocyanidins, but increased the concentrations of flavanols. In the same variety (Tempranillo, two-year trial), Diago et al. [30] reported that leaf removal also might significantly increase the accumulation of anthocyanins in berries, but not in every year what is again consistent with our findings (see Supplementary Tables S5 and S6).

In wine, the concentration of total phenols, total tartaric acid esters and total flavanols very regularly increased from no leaf removal (control), over late leaf removal, and were the highest in ELR treatments, in each experimental year (Table 4, Figure 5b). In all treatments the profiles of these four compounds were statistically different (based on MRPP analysis). The total phenols content in ELR wine (average across three years $1924 \pm 144 \mathrm{mg} \mathrm{L}^{-1}$ ) was by $15 \%$ higher than in LLR wine and about $42 \%$ higher than in the control wine. Likewise, total flavanols in ELR wine (average for three years $335 \pm 62 \mathrm{mg} \mathrm{L}^{-1}$ ) were 1.22-fold higher than in LLR, and 1.79-fold higher compared to the control wine (main effect of leaf removal treatment). Early leaf removal further caused an increase of the content of total tartaric acid esters in wine by $18 \%$ and by $38 \%$ relative to the LLR and control treatment, respectively. Finally, although the content of total anthocyanins in wine largely depended on the experimental year (Supplementary Table S6), in the representative 2012 year, it also clearly had the same pattern (ELR > LLR > Control, Table 4).

Light stimulates expression and activity of a number enzymes involved in the synthesis of phenolic compounds, and shading reduces these processes [6]. Although light is essential for the production of anthocyanins, direct exposure of clusters to sun light is much more important for the production of flavanols then for the accumulation of anthocyanins; therefore, various authors proposed flavanols as some kind of markers for light exposure and microclimate of clusters [12,28,33-38]. For instance, sun-exposed clusters had greater berry skin concentrations of total and individual (e.g., myricetin, quercetin and kaempferol) flavanols than in shaded clusters of Merlot [36]. These findings are in agreement with our results (Figures 5 and 6 ), where anthocyanins were not correlated to the statistically significant PCA axis, while flavanols strongly corresponded to the gradient induced by leaf removal along the PCA axis 1 . According to various authors, the shaded clusters showed significantly lower anthocyanins concentration than those exposed to sun $[7,28,32,39]$.

Furthermore, the detailed profile of flavanols and antocyanins in response to leaf removal treatments in berry skin (Table 5, Figure 6a) and in wine (Table 6, Figure 6b) are shown for the year 2012. This year incidentally happened to be rather typical for the Eastern Serbia terroir (see Table 1 and Supplemental Table S7). In fact, 2011 was rather dry and 2013 was cooler and more humid than the average weather conditions of this region. All the treatments (characterized by 12 phenolic compounds) were statistically significantly different (MRPP test for 2012 data, skin and wine, not shown). The skin concentrations of total flavanols measured over three-year experiment were the highest in ELR treatments (Table 3, Figure 5a), and, consistently, all the six detected flavanol compounds (except rutin) had the highest concentration in the ELR treatment of 2012 (Table 5, Figure 6a). Like with total flavanols (Table 3, Figure 5a), the differences in 7 phenolic compounds detected in skin were not consistent between LLR and control. The accumulation of kaempferol, quercetin and morin in particular was 2-fold higher in ELR than in the control in 2012 (Table 5). The prominent accumulation of flavanols in the berry skin (catechin, quercetin, 
quercetin-glucoside, morine, myricetine, and kaempferol) in the ELR treatment (Table 5, Figure 6a) is in agreement with findings of Downey et al. [6] in Shiraz, Ćirković et al. [28] in Prokupac, and Spayd et al. [36] in Merlot. The skin concentrations of total anthocyanins were the highest in ELR treatments in each experimental year (Table 3, Figure 5a), but their values highly varied between years (as discussed previously). In the samples from 2012 (Table 5, Figure 6a), five out of six detected anthocyanins had the highest concentration in the ELR treatment. Malvidin-3-glucoside was the dominant anthocyanin in the berry skin of Cabernet Sauvignon in 2012 (Table 5), which is in accordance with the findings of Ristic et al. [32] in the berry skin of Shiraz. Malvidin-3-glucoside showed the highest concentration in ELR treatment which differed significantly from the other two treatments (Table 5, Figure 6a). On the other hand, the concentrations of the three anthocyanins (peonidin-3-glucoside, petunid-3-glucoside, delphidin-3-glucoside) in berry skin were significantly lower in the LLR treatment than in ELR and control treatments. Relative to the control, the ELR treatment increased the concentration of anthocyanin compounds by up to $40 \%$ in 2012 (Table 5) and Spayd et al. [36].

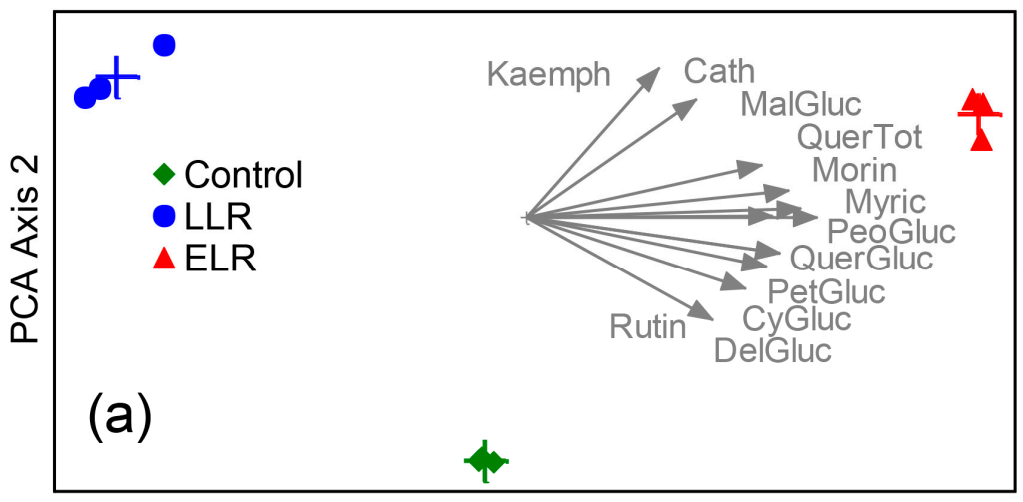

PCA Axis $1(79.1 \%)$

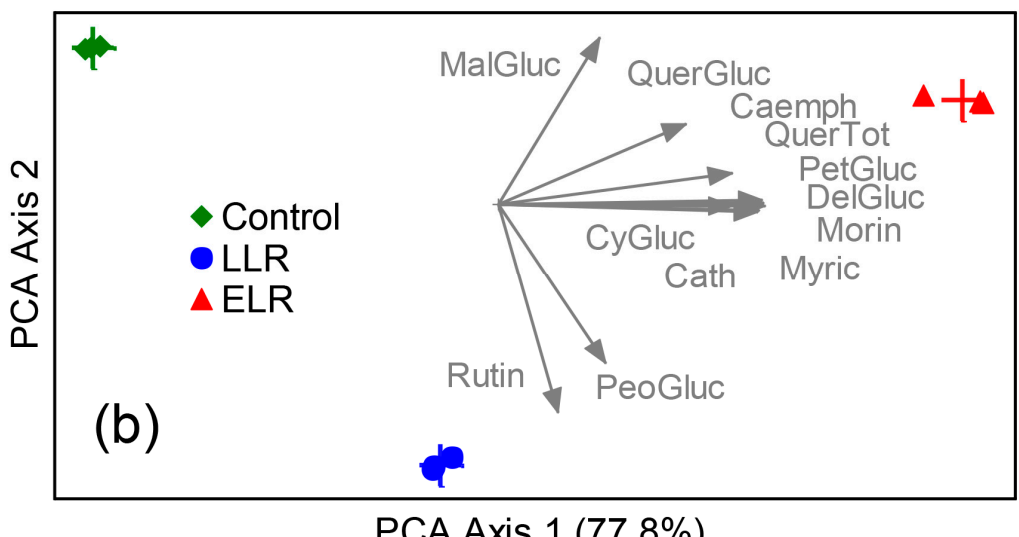

PCA Axis $1(77.8 \%)$

Figure 6. Major gradients (PCA ordination) in the concentrations of 12 chemical compounds determined by HPLC in the berry skin (a) and the wine (after 6 months of aging) (b) of Cabernet Sauvignon across the three treatments: Control (no leaf removal); LLR (late leaf removal) and ELR (early leaf removal). The values in parenthesis denote the proportion of variance represented by each statistically significant PCA axis. The angles and lengths of the radiating lines indicate the direction and strength of relationships of the variables with the ordination scores. Data matrix: 9 samples collected in one representative year (2012), 12 variables, correlation cross-product matrix, Euclidean distance, no rotation. Samples (3 per leaf removal treatment) are shown, together with group centroids (crosses) which point the average position of a sample within each treatment. Chemical compounds are abbreviated as in Tables 5 and 6 . All the variables were correlated with the ordination scores by $>35 \%$. 
Table 5. Effects of leaf removal timing on the concentrations ( $\mathrm{mg} \mathrm{g}^{-1} \mathrm{FW}$ ) of different phenolic compounds (flavanols and anthocyanins) in the grape berry skin determined by HPLC. LLR, late leaf removal; ELR, early leaf removal. The results from representative year (2012) are shown. Data are means of three replicates \pm SD. Different letters in a row denote significant difference between parameter means after Tukey's test following one-way ANOVA $(p<0.05)$.

\begin{tabular}{ccccc}
\hline Compounds & Abbreviation & Control & LLR & ELR \\
\hline Malvidin-3-glucoside $^{1}$ & MalGluc & $20.119 \pm 0.002^{\mathrm{a}}$ & $20.136 \pm 0.004^{\mathrm{b}}$ & $22.306^{\mathrm{a}} \pm 0.00^{\mathrm{c}}$ \\
Peonidin-3-glucoside $^{1}$ & PeoGluc & $2.110 \pm 0.00^{\mathrm{b}}$ & $1.563 \pm 0.004^{\mathrm{a}}$ & $2.953 \pm 0.002^{\mathrm{c}}$ \\
Petunidin-3-glucoside $^{1}$ & PetGluc & $2.675 \pm 0.003^{\mathrm{b}}$ & $2.1830 \pm 0.0008^{\mathrm{a}}$ & $2.842^{\mathrm{a}} \pm 0.001^{\mathrm{c}}$ \\
Cyanidin-3-glucoside $^{1}$ & CyGluc & $0.434 \pm 0.002^{\mathrm{b}}$ & $0.235 \pm 0.00^{\mathrm{a}}$ & $0.479 \pm 0.000^{\mathrm{c}}$ \\
Delphinidin-3-glucoside $^{1}$ & DelGluc & $3.411 \pm 0.0014^{\mathrm{b}}$ & $2.534 \pm 0.00^{\mathrm{a}}$ & $3.507^{\mathrm{a}} \pm 0.003^{\mathrm{c}}$ \\
Quercetin-glucoside $^{2}$ & QuerGluc & $0.326 \pm 0.004^{\mathrm{b}}$ & $0.225 \pm 0.00^{\mathrm{a}}$ & $0.357^{\mathrm{a}} \pm 0.004^{\mathrm{c}}$ \\
Quercetin $^{2}$ & QuerTot & $0.177 \pm 0.004^{\mathrm{b}}$ & $0.156 \pm 0.00^{\mathrm{a}}$ & $0.324 \pm 0.003^{\mathrm{c}}$ \\
Rutin $^{2}$ & Rutin & $0.527 \pm 0.002^{\mathrm{c}}$ & $0.266 \pm 0.00^{\mathrm{a}}$ & $0.519 \pm 0.00^{\mathrm{b}}$ \\
Morin $^{2}$ & Morin & $0.08 \pm 0.0009^{\mathrm{b}}$ & $0.066 \pm 0.00^{\mathrm{a}}$ & $0.116 \pm 0.004^{\mathrm{c}}$ \\
Myricetin $^{2}$ & Myric & $0.039 \pm 0.0005^{\mathrm{a}}$ & $0.034 \pm 0.00^{\mathrm{a}}$ & $0.051 \pm 0.00^{\mathrm{b}}$ \\
Kaempferol $^{2}$ & Kaemph & $0.029 \pm 0.0007^{\mathrm{a}}$ & $0.045 \pm 0.00^{\mathrm{b}}$ & $0.065 \pm 0.003^{\mathrm{c}}$ \\
Catechin $^{2}$ & Cath & $5.282 \pm 0.008^{\mathrm{a}}$ & $5.438 \pm 0.00^{\mathrm{b}}$ & $5.886 \pm 0.004^{\mathrm{c}}$ \\
\hline
\end{tabular}

${ }^{1}$ Anthocyanins; ${ }^{2}$ Flavonols.

Table 6. Effects of leaf removal on the concentrations $\left(\mathrm{mg} \mathrm{L}^{-1}\right)$ of different phenolic compounds (flavanols and anthocyanins) in wine (after 6 months of aging) determined by HPLC. LLR, late leaf removal; ELR, early leaf removal. The results from representative year (2012) are shown. Data are means of three replicates \pm SD. Different letters in a row denote significant difference between parameter means after Tukey's test following one-way ANOVA $(p<0.05)$.

\begin{tabular}{ccccc}
\hline Compounds & Abbreviation & Control & LLR & ELR \\
\hline Malvidin-3-glucoside $^{1}$ & MalGluc & $851.4 \pm 0.02^{\mathrm{b}}$ & $787.21 \pm 0.04^{\mathrm{a}}$ & $921.40 \pm 0.03^{\mathrm{c}}$ \\
Peonidin-3-glucoside $^{1}$ & PeoGluc & $11.1 \pm 0.01^{\mathrm{a}}$ & $18.2^{\mathrm{a}} \pm 0.05^{\mathrm{c}}$ & $16.4 \pm 0.03^{\mathrm{b}}$ \\
Petunidin-3-glucoside $^{1}$ & PetGluc & $60.4 \pm 0.02^{\mathrm{a}}$ & $67.1 \pm 0.02^{\mathrm{b}}$ & $81.5^{\mathrm{b}} \pm 0.03^{\mathrm{c}}$ \\
Cyanidin-3-glucoside $^{1}$ & CyGluc & $10.2 \pm 0.02^{\mathrm{a}}$ & $10.9 \pm 0.03^{\mathrm{b}}$ & $11.7^{\mathrm{a}} \pm 0.7^{\mathrm{c}}$ \\
Delphinidin-3-glucoside $^{1}$ & DelGluc & $28.4 \pm 0.03^{\mathrm{a}}$ & $41.0 \pm 0.02^{\mathrm{b}}$ & $52.1^{\mathrm{a}} \pm 0.02^{\mathrm{c}}$ \\
Quercetin-glucoside $^{2}$ & QuerGluc & $19.8 \pm 0.04^{\mathrm{b}}$ & $18.2^{\mathrm{b}} \pm 0.02^{\mathrm{a}}$ & $26.80^{\mathrm{a}} \pm 0.0^{\mathrm{c}}$ \\
Quercetin $^{2}$ & QuerTot & $4.9 \pm 0.02^{\mathrm{a}}$ & $11.2 \pm 0.02^{\mathrm{b}}$ & $27.1^{\mathrm{b}} \pm .04^{\mathrm{c}}$ \\
Rutin $^{2}$ & Rutin & $9.5 \pm 0.03^{\mathrm{a}}$ & $15.0 \pm 0.03^{\mathrm{c}}$ & $12.6^{\mathrm{a}} \pm 0.02^{\mathrm{b}}$ \\
Morin $^{2}$ & Morin & $3.4 \pm 0.04^{\mathrm{a}}$ & $5.7 \pm 0.01^{\mathrm{b}}$ & $7.6 \pm 0.02^{\mathrm{c}}$ \\
Myricetin $^{2}$ & Myric & $1.9 \pm 0.03^{\mathrm{a}}$ & $4.5 \pm 0.02^{\mathrm{b}}$ & $7.6 \pm 0.04^{\mathrm{c}}$ \\
Kaempferol $^{2}$ & Kaemph & $3.5 \pm 0.02^{\mathrm{a}}$ & $3.6 \pm 0.04^{\mathrm{a}}$ & $3.9 \pm 0.01^{\mathrm{b}}$ \\
Catechin $^{2}$ & Cath & $38.4 \pm 0.04^{\mathrm{a}}$ & $42.1 \pm 0.03^{\mathrm{b}}$ & $46.2^{\mathrm{a}} \pm 0.04^{\mathrm{c}}$ \\
\hline
\end{tabular}

${ }^{1}$ Anthocyanins; ${ }^{2}$ Flavonols.

In wine, the concentrations of total flavanols and total anthocyanins measured over three-year experiment were also the highest in ELR treatments (Table 4, Figure 5b), and, consistently, all the 11 detected anthocyanin and flavanol compounds (except rutin) were the highest in the ELR treatment of 2012 (Table 6, Figure 5b). The significant gradient in increase of total flavanols (Control $<$ LLR $<$ ELR, PCA Axis 1, Figure 6b) was best reflected in the gradual increase of morin and myricetin in year 2012 (PCA Axis 1 in Figure 6b). This trend was in fact observed with all the detected flavanols except rutin (Table 6). Across the three-year period, the ELR treatment increased total phenols by $22 \%$ and by $80 \%$ in comparison with the LLR and the control, respectively. In the year 2012, specifically, the increase of total phenols in ELR were by $10 \%$ and by about $200 \%$ relative to the LLR and the control, respectively (Table 4). This increase in 2012 was not uniform for all the detected flavanols: In was most prominent in quercetin (up to 5-fold) and myricetin (up to 4-fold), and least in kaempferol (Table 6). Malvidin 3-glucoside was the dominant anthocyanin in wine, like in berries in 2012 (Table 5). Total anthocyanins in wine were the highest in year 2012 (Table 4), and decisively modified by experimental year (Supplementary Table S6). So the better effect of ELR on concentration of total anthocyanins in wine (Table 4) was found for years 2011 and 2012, but not for 2013 (the season with less insolation, Table 1). This suggests that three year trials might not be sufficient to firmly establish the effect 
of leaf removal timing on total anthocyanins in wine. In samples from 2012, four out of five detected anthocyanins in wine were the highest in the ELR treatments (Table 6). The strongest increase in ELR treatment was found for delphinidin-3-glucoside (27\% relative to the LLR, and $83 \%$ relative to the control. The changes in phenolic profiles shown here are only illustrative and have no predicative power. For instance, while in one year we found that ELR increases delfphidine-, malvidine-, cyanindin-, and petunidin-3 glucosides (compared to ELR and control, Table 6), Ivanisevic et al. reported, on the same variety Cabernet, in Serbia, also for one year, a respective effect for delfphidin- and cyanindin-, no effect on petunidin-, and a decrease of malvidine-3 glucosides.

Overall, the general ELR phenolic profile (in the year 2012) was distinguished from the other treatments primarily by the highest concentrations of total quercetin and myricetin in both skin and wine, followed by the highest morin in the skin and the highest petunidinglucoside in the wine (Figure 6). Interestingly, late defoliation prominently differed from the other two treatments by the lowest concentrations of rutin, peonidin-, cyanidin-, and delphinidine-glucosides in skin tissue (Figure 6a), while in the wine this treatment was set apart by the highest concentrations of rutin and peonidin-glucoside (Figure $6 b$ ).

\section{Conclusions}

Both early and late leaf removal treatments increased the content of sugars in fresh juice and alcohol in wine, compared to the control. In a three-year field experiment with pronounced interannual variability of temperature and precipitation, the early timing of leaf removal (ELR) showed a very clear effect on a decrease of cluster weight, weight of berries in a cluster and weight of a single berry, and on an increase of skin share in a berry (compared to LLR and control). Also, ELR resulted in the lowest grape yield. Early leaf removal furthermore increased the content of total phenols, tartaric acid esters, anthocyanins and flavanols in both berry skin and wine, with the exception of the total anthocyanins content in 2013, which was atypically humid. Indeed, ELR treatment showed irrespectively of very different growth seasons. In the representative year (2012), the ELR most prominently increased the content of the flavanols, myricetin, and quercetine, in both berry skin and wine, while with respect to anthocyanins the ELR caused the highest increase of peonidin-3-glucoside in skin and the highest increase of delphinidin-3-glucoside in wine.

This work clearly demonstrated the positive impact of early leaf removal on the chemical composition of berries and wine in a rather warm and arid temperature during veraison to harvest period (July-September) of continental climate in Eastern Serbia. Therefore, this measure can be recommended to increase wine quality of Cabernet Sauvignon, but has to be carefully considered together with the other factors that affect wine quality (e.g., climatic and soil conditions, training system, and winemaking technology).

Supplementary Materials: The following are available online at https:/ /www.mdpi.com/2073-439 5/11/2/238/s1, Table S1: Variance partitioning based on a two-way ANOVA with the interaction term for the vegetative growth and yield components, attributable to treatment factors; Table S2: Variance partitioning based on a two-way ANOVA with the interaction term for the parameters (total soluble solids (TSS)) and total acids in fresh grape juice, attributable to treatment factors; Table S3: Variance partitioning based on a two-way ANOVA with the interaction term for the content of alcohol, total acids and volatile acids in wine, attributable to treatment factors; Table S4: Variance partitioning based on a two-way ANOVA with the interaction term for the share of skin (\%) in a fresh berry mass attributable to treatment factors; Table S5: Variance partitioning based on a two-way ANOVA with the interaction term for the concentration of four major groups of chemical compounds in berry skin, attributable to treatment factors; Table S6: Variance partitioning based on a two-way ANOVA with the interaction term for the concentration of four major groups of chemical compounds in wine, attributable to treatment factors; Table S7: Average temperature $\left({ }^{\circ} \mathrm{C}\right)$, precipitation $(\mathrm{mm})$ and insolation (h) during the bud burst to harvest period (2011-2013). 


\begin{abstract}
Author Contributions: Conceptualization, D.S., S.T., and M.N.; methodology, D.S. and N.N.; software, N.N.; validation, D.S., M.N., N.N., and L.K.; formal analysis, D.S. and N.N.; investigation, D.S.; writing-original draft preparation, D.S. and N.N.; writing-review and editing, M.N. and N.N.; visualization, N.N. and L.K.; supervision, S.T. and M.N.; funding acquisition, M.N. All authors have read and agreed to the published version of the manuscript.
\end{abstract}

Funding: This research was supported by the Serbian Ministry of Education, Science and Technological Development (Contract No. 451-03-68/2020-14/200053).

Institutional Review Board Statement: Not relevant.

Informed Consent Statement: Not applicable.

Data Availability Statement: No new data were created or analyzed in this study. Data sharing is not applicable to this article.

Conflicts of Interest: The authors declare no conflict of interest.

\title{
References
}

1. Poni, S.; Gatti, M.; Bernizzoni, F.; Civardi, S.; Bobeica, N.; Magnanini, E.; Palliotti, A. Late leaf removal aimed at delaying ripening in cv. Sangiovese: Physiological assessment and vine performance. Aust. J. Grape Wine Res. 2013, 19, 378-387. [CrossRef]

2. Bondada, B.; Covarrubias, J.I.; Tessarin, P.; Boliani, A.C.; Marodin, G.; Rombolà, A.D. Post-veraison shoot trimming reduces cluster compactness without compromising fruit quality attributes in organically-grown Sangiovese grapevines. Am. J. Enol. Vitic. 2016, 67, 206-211. [CrossRef]

3. Smart, R.E.; Smith, S.M.; Winchester, R.V. Light quality and quantity effects on fruit ripening for Cabernet Sauvignon. Am. J. Enol. Vitic. 1988, 39, 250-258.

4. Rojas-Lara, B.A.; Morrison, J.C. Differential effects of shading fruit or foliage on the development and composition of grape berries. Vitis 1989, 28, 199-208.

5. Hunter, J.J.; De Villiers, O.T.; Watts, J.E. The effect of partial defoliation on quality characteristics of Vitis vinifera L. cv. Cabernet Sauvignon grapes. Skin color, skin sugar and wine quality. Am. J. Enol. Vitic. 1991, 42, 13-18.

6. Downey, M.O.; Harvey, J.S.; Robinson, S.P. The effect of bunch shading on berry development and flavonoid accumulation in Shiraz grapes. Aust. J. Grape Wine Res. 2004, 10, 55-73. [CrossRef]

7. Chorti, E.; Gudoni, S.; Ferrandino, A.; Novello, V. Effect of different cluster sunlight exposure levels on ripening and anthocyanin accumulation in Nebbiolo grapes. Am. J. Enol. Vitic. 2010, 61, 23-30.

8. Risco, D.; Perez, D.; Yeves, A.; Castel, J.R.; Intrigliolo, D.S. Early defoliation in a temperate warm and semiarid Tempranillo vineyard: Vine performance and grape composition. Aust. J. Grape Wine Res. 2014, 20, 111-122. [CrossRef]

9. Sternad Lemut, M.; Sivilotti, P.; Franceschi, P.; Wehrens, R.; Vrhovsek, U. Use of metabolic profiling to study grape skin polyphenol behavior as a result of canopy microclimate manipulation in a Pinot Noir vineyard. J. Agric. Food Chem. 2013, 61, 8976-8986. [CrossRef]

10. Dokoozlian, N.K.; Kliewer, W.M. The light environment within grapevine canopies. I. Description and seasonal changes during fruit development. Am. J. Enol. Vitic. 1995, 46, 209-217.

11. Tarara, J.M.; Lee, J.; Spayd, S.E.; Scagel, C.F. Berry temperature and solar radiation alter acylation, proportion, and concentration of anthocyanin in Merlot grapes. Am. J. Enol. Vitic. 2008, 59, 235-247.

12. Diago, M.P.; Vilanova, M.; Tardaguila, J. Effects of timing of manual and mechanical early defoliation on the aroma of Vitis vinifera L. Tempranillo wine. Am. J. Enol. Vitic. 2010, 61, 382-391.

13. Bergqvist, J.; Dokoozlian, N.; Ebisuda, N. Sunlight exposure and temperature effects on berry growth and composition of Cabernet Sauvignon and Grenache in the central San Joaquin Valley of California. Am. J. Enol. Vitic. 2001, 52, 1-7.

14. German, J.B.; Walzem, R.L. The health benefits of wine. Annu. Rev. Nutr. 2000, 20, 561-593. [CrossRef]

15. Tessarin, P. Effects and Modes of Action of Canopy Management Practices on Vine Physiology and Berry Composition in Organically-Cultivated cv. Sangiovese (Vitis vinifera L.). Ph.D. Thesis, University of Bologna, Bologna, Italy, 2016.

16. Poni, S.; Bernizzoni, F.; Briola, G. Effects of early leaf removal on cluster morphology, shoot efficiency and grape quality in two Vitis Vinifera cultivars. Acta Hort. 2005, 689, 217-226. [CrossRef]

17. Intrieri, C.; Filippetti, I.; Allegro, G.; Centinari, M.; Poni, S. Early defoliation (hand vs mechanical) for improved crop control and grape composition in Sangiovese (Vitis vinifera L.). Aust. J. Grape Wine Res. 2008, 14, 25-32. [CrossRef]

18. Baiano, A.; De Gianni, A.; Previtali, M.A.; Del Nobile, M.A.; Novello, V.; de Palma, L. Effects of defoliation on quality attributes of Nero di Troia (Vitis vinifera L.) grape and wine. Food Res. Int. 2015, 75, 260-269. [CrossRef]

19. Mijowska, K.; Ochmian, I.; Oszmianski, J. Impact of cluster zone leaf removal on grapes cv. Regent on polyphenol content by the UPLC-PDA/MS method. Molecules 2016, 21, 1688. [CrossRef]

20. Beck, H.E.; Zimmermann, N.E.; McVicar, T.R.; Vergopolan, N.; Berg, A.; Wood, E.F. Present and future Köppen-Geiger climate classification maps at 1-km resolution. Sci. Data 2018, 5, 180214. [CrossRef] 
21. Anđelković, G.; Živković, N. Precipitation as an adverse climatic phenomenon in Negotin. Bull. Serb. Geogr. Soc. 2007, 87, 51-62. (In Serbian)

22. Lorenz, D.H.; Eichhorn, K.W.; Bleiholder, H.; Klose, R.; Meier, U.; Weber, E. Growth stages of the grapevine: Phenological growth stages of the grapevine (Vitis vinifera L. ssp. vinifera). Codes and descriptions according to the extended BBCH scale. Aust. J. Grape Wine Res. 1995, 1, 100-103. [CrossRef]

23. Mazza, G.; Fukumoto, L.; Delaquis, P.; Girard, B.; Ewert, B. Anthocyanins, phenolics, and color of Cabernet Franc, Merlot and Pinot Noir wines from British Columbia. J. Agric. Food Chem. 1999, 47, 4009-4017. [CrossRef] [PubMed]

24. Di Stefano, R. Metodi chimici nella caratterizzione varietale. Riv. Vitic. Enol. 1996, 1, 51-56.

25. Mielke, P.W.J.; Berry, K.J. Permutation Methods: A Distance Function Approach; Springer: Berlin, Germany, 2001.

26. Moreno, D.; Vilanova, M.; Gamero, E.; Intrigliolo, D.; Talaverano, I.; Uriarte, D.; Valdes, E. Effects of preflowering leaf removal on phenolic composition of Tempranillo in the semiarid terroir of Western Spain. Am. J. Enol. Vitic. 2015, 66, 204-211. [CrossRef]

27. Tardaguila, J.; Diago, M.P.; de Toda, F.M.; Poni, S.; Vilanova, M. Effects of timing of leaf removal on yield, berry maturity, wine composition and sensory properties of cv. Grenache grown under non irrigated conditions. J. Int. Sci. Vigne Vin 2008, 42, 221-229. [CrossRef]

28. Ćirković, D.; Matijašević, S.; Deletić, N.; Ćirković, B.; Gašić, U.; Sredojević, M.; Jovanović, Z.; Djurić, V.; Tešić, Ž. The effect of early and late defoliation on phenolic composition and antioxidant properties of Prokupac variety grape berries (Vitis vinifera L.). Agronomy 2019, 9, 822. [CrossRef]

29. Bledsoe, A.M.; Kliewer, W.M.; Marois, J.J. Effects of timing and severity of leaf removal on yield and fruit composition of Sauvignon Blanc grapevines. Am. J. Enol. Vitic. 1988, 39, 49-54.

30. Diago, M.P.; Ayestarán, B.; Guadalupe, Z.; Poni, S.; Tardáguila, J. Impact of prebloom and fruit set basal leaf removal on the flavonol and anthocyanin composition of Tempranillo grapes. Am. J. Enol. Vitic. 2012, 63, 367-376. [CrossRef]

31. Ivanišević, D.; Kalajdžić, M.; Drenjančević, M.; Puškaš, V.; Korać, N. The impact of cluster thinning and leaf removal timing on the grape quality and concentration of monomeric anthocyanins in Cabernet-Sauvignon and Probus (Vitis vinifera L.) wines. OENO One 2020, 1, 63-74. [CrossRef]

32. Ristic, R.; Downey, M.O.; Iland, P.G.; Bindon, K.; Francis, I.L.; Herderich, M.J.; Robinson, S.P. Exclusion on sunlight from Shiraz grapes alters wine colour, tanninand sensory properties. Aust. J. Grape Wine Res. 2007, 13, 53-65. [CrossRef]

33. Coombe, B.G. Research on development and ripening of the grape berry. Am. J. Enol. Vitic. 1992, 43, 101-110.

34. Poni, S.; Casalini, L.; Bernizzoni, F.; Civardi, S.; Intrieri, C. Effect of early defoliation on shoot photosynthesis, yield components and grape composition. Am. J. Enol. Vitic. 2006, 57, 397-407.

35. Crippen, D.D.; Morrison, J.C. The effects of sun exposure on the compositional development of Cabernet Sauvignon berries. Am. J. Enol. Vitic. 1986, 37, 235-242.

36. Spayd, S.E.; Tarara, J.M.; Mee, D.L.; Ferguson, J.C. Separation of sunlight and temperature effects on the composition of Vitis vinifera cv. Merlot berries. Am. J. Enol. Vitic. 2002, 53, 171-182.

37. Keller, M.; Hrazdina, G. Interaction of nitrogen availability during bloom and light intensity during veraison: Effects on anthocyanin and phenolic development during grape ripening. Am. J. Enol. Vitic. 1998, 49, 341-349.

38. Pereira, G.E.; Gaudillere, J.P.; Pieri, P.; Hilbert, G.; Maucourt, M.; Deborde, C.; Moing, A.; Rolin, D.l. Microclimate influence on mineral and metabolic profiles of grape berries. J. Agric. Food Chem. 2006, 54, 6765-6775. [CrossRef]

39. Morrison, J.C.; Noble, A.C. The effects of leaf and cluster shading on the composition of Cabernet Sauvignon grapes and on fruit and wine sensory properties. Am. J. Enol. Vitic. 1990, 41, 193-200. 